\title{
Эффект увлечения в нанокомпозитной пленке Ag/Pd: генерация двуполярных импульсов
}

\author{
(C) Г.М. Михеев ${ }^{1}$, А.С. Саушин ${ }^{1}$, В.М. Стяпшин ${ }^{1}$, Ю.П. Свирко ${ }^{2}$ \\ ${ }^{1}$ Институт механики Удмуртского федерального \\ исследовательского центра УрО РАН, \\ Ижевск, Россия \\ ${ }^{2}$ Институт фоотоники, Университет Восточной Финляндии, \\ Йоэнсуу, Финляндия \\ E-mail: mikheev@udman.ru
}

Поступило в Редакцию 12 апреля 2018 г.

Впервые исследованы особенности генерации продольного фототока в нанокомпозитных пленках $\mathrm{Ag} / \mathrm{Pd}$ при наклонном падении импульсного лазерного излучения наносекундной длительности в области длин волн $1350-4000 \mathrm{~nm}$. Пленки толщиной $20 \mu \mathrm{m}$, состоящие из нанокристаллитов твердого раствора $\mathrm{Ag}-\mathrm{Pd}$ и оксида палладия $\mathrm{PdO}$, получены по толстопленочной технологии. Исследовано влияние длины волны на импульсы фототока при $p$ - и $s$-поляризациях лазерной накачки. Показано, что импульс фототока при $s$-поляризованной накачке в диапазоне длин волн 1350-4000 nm является однополярным, а при $p$-поляризации в зависимости от длины волны он может быть однополярным и двуполярным. Полученные результаты объясняются одновременной генерацией фототока за счет эффекта увлечения и поверхностного фотогальванического эффекта.

DOI: 10.21883/PJTF.2018.18.46616.17329

Эффект увлечения (ЭУ), впервые обнаруженный в работе [1], обусловлен тем, что при поглощении фотона носителем заряда, последний получает от фотона не только энергию, но и импульс. В результате в среде возникает фототок (фотоэдс), полярность которого зависит от направления волнового вектора падающего излучения. При импульсном лазерном возбуждении фототок ЭУ возникает в виде однополярного импульса. В массивных металлических образцах фототок ЭУ очень мал [2], однако в пленочных электропроводящих структурах при наклонном 
падении излучения он может быть значительным [3]. В последнее время появились публикации, посвященные наблюдению и исследованию ЭУ в различных наноразмерных структурах [4-10]. Такие исследования представляют интерес с точки зрения различных приложений, в частности для разработки и создания не содержащих оптических элементов анализаторов поляризации лазерного излучения $[11,12]$.

При наклонном падении излучения на пленочную структуру фототок ЭУ можно наблюдать в плоскости падения (продольный фототок) и в направлении, перпендикулярном плоскости падения (поперечный фототок) (см., например, [5,13]). В наших недавних публикациях $[14,15]$ были представлены исследования поперечного фототока ЭУ в серебропалладиевых $(\mathrm{Ag} / \mathrm{Pd})$ нанокомпозитных пленках. Было установлено, что в этих пленках в широком спектральном диапазоне $266-2100 \mathrm{~nm}$ наблюдается фототок, зависящий от степени циркулярной поляризации падающего излучения. Было показано, что в инфракрасном диапазоне $1064-2100 \mathrm{~nm}$ полярность фототока однозначно определяется знаком циркулярной поляризации (направлением вращения вектора электрического поля) возбуждающего излучения. Между тем особенности продольного фототока ЭУ в нанокомпозитных пленках $\mathrm{Ag} / \mathrm{Pd}$ исследовались только в спектральном диапазоне 266-1064 nm [16]. Целью настоящей работы является наблюдение и исследование продольного фототока в нанокомпозитных пленках $\mathrm{Ag} / \mathrm{Pd}$ в инфракрасной области $1350-4000 \mathrm{~nm}$.

В работе исследовались пленки $\mathrm{Ag} / \mathrm{Pd}$, полученные на керамической подложке по толстопленочной технологии при температуре вжигания $878 \mathrm{~K}$ [17]. Пленки с проводимостью р-типа имели размер $20 \times 20 \mathrm{~mm}$ при толщине около $20 \mu \mathrm{m}$. Рентгеноструктурный анализ показал, что исследуемые пленки состоят из твердого раствора $\mathrm{Ag}-\mathrm{Pd}$, оксида палладия $\mathrm{PdO}$ и оксида серебра $\mathrm{Ag}_{2} \mathrm{O}$ в весовом соотношении $80.3 \%, 18.7 \%$ и $1 \%$ соответственно. По ширине рентгеновской дифракционной линии установлено, что минимальный размер кристаллитов $\mathrm{Ag}-\mathrm{Pd}$ и $\mathrm{PdO}$ составляет 39 и $28 \mathrm{~nm}$ соответственно [17]. Для измерения фототока пленки снабжались двумя параллельными пленочными электродами $A$ и $B$, выполненными из серебра. Они располагались на противоположных сторонах квадратной пленки между подложкой и самой пленкой. Омическое сопротивление между измерительными электродами составляло $29 \Omega$.

Письма в ЖТФ, 2018, том 44, вып. 18 
В экспериментах использовался перестраиваемый по длине волны $\lambda$ $(1350-4000 \mathrm{~nm})$ лазер, состоящий из параметрического генератора и усилителя света. Длительность лазерных импульсов $\tau_{p}$ составляла $7 \mathrm{~ns}$, a энергия $E_{\text {in }}$ не превышала $2 \mathrm{~mJ}$. Эксперименты проводились по оптической схеме, представленной на рис. 1 (вставка). С помощью поворота полуволновой пластины на угол $\varphi$ менялась ориентация плоскости поляризации, определяемая углом $\Phi$ (углом между плоскостью поляризации и плоскостью падения излучения на пленку, $\Phi=2 \varphi)$. При $\varphi=0$ угол поляризации $\Phi=0$, и на пленку падает $p$-поляризованное излучение. При $\varphi=45^{\circ}$ угол поляризации $\Phi=90^{\circ}$, и на пленку падает $s$-поляризованное излучение. Измерительные электроды подсоединялись к входу широкополосного цифрового осциллографа с входным сопротивлением $r=50 \Omega$. В экспериментах измерялись и записывались экстремальные значения импульсов напряжения и временны́е параметры одиночных импульсов фотоэдс, возникающих между электродами $A$ и $B$ при облучении пленки. Продольный фототок $i_{x}$ (далее фототок), лежащий в плоскости падения $\sigma$, определялся по формуле $i_{x}=U_{x} / r$, где $U_{x}$ - экстремальные значения импульсов фотоэдс. В зависимости от угла падения $\alpha$ и поляризации падающего излучения значения $U_{x}$ могли быть положительными, отрицательными или равными нулю.

Эксперименты, проведенные на длинах волн 1350-1550 nm, показали, что для $p$ - и $s$-поляризаций выполняются следующие соотношения: $i_{x}=0$ при $\alpha=0 ; i_{x}>0$ при $\alpha>0 ; i_{x}<0$ при $\alpha<0$; для любого угла падения $\alpha$ справедливо равенство $i_{x}(-\alpha)=-i_{x}(\alpha)$. Все эти закономерности характерны для ЭУ в пленочных структурах (см., например, $[3,8])$. На рис. 1 показана экспериментально полученная зависимость коэффициента преобразования $\eta_{x}$ лазерной мощности $P_{i n}$ в фототок $i_{x}$ при $\lambda=1550 \mathrm{~nm}$ в зависимости от угла поляризации $\Phi$, где $\eta_{x}=i_{x} / P_{i n}, P_{i n}=E_{i n} / \tau_{p}$. Видно, что величина $\eta_{x}$ максимальна при $s$-поляризации и минимальна при $p$-поляризации. Влияние угла поляризации $\Phi$ на $\eta_{x}$ хорошо описывается функцией $\eta_{x}(\Phi) \propto[C-\cos 2 \Phi]$, где $C-$ постоянная. Дальнейшие эксперименты показали, что при $s$ поляризованном излучении накачки и при $\alpha>0$ фототок в широком диапазоне длин волн $(1350-4000 \mathrm{~nm})$ появляется в виде положительного однополярного импульса (рис. 2, вставка), длительность которого практически не зависит от длины волны. Однако форма импульса фототока при $p$-поляризации существенно зависит от длины волны накачки (рис. 2). В области длин волн менее $1670 \mathrm{~nm}$ продольный 


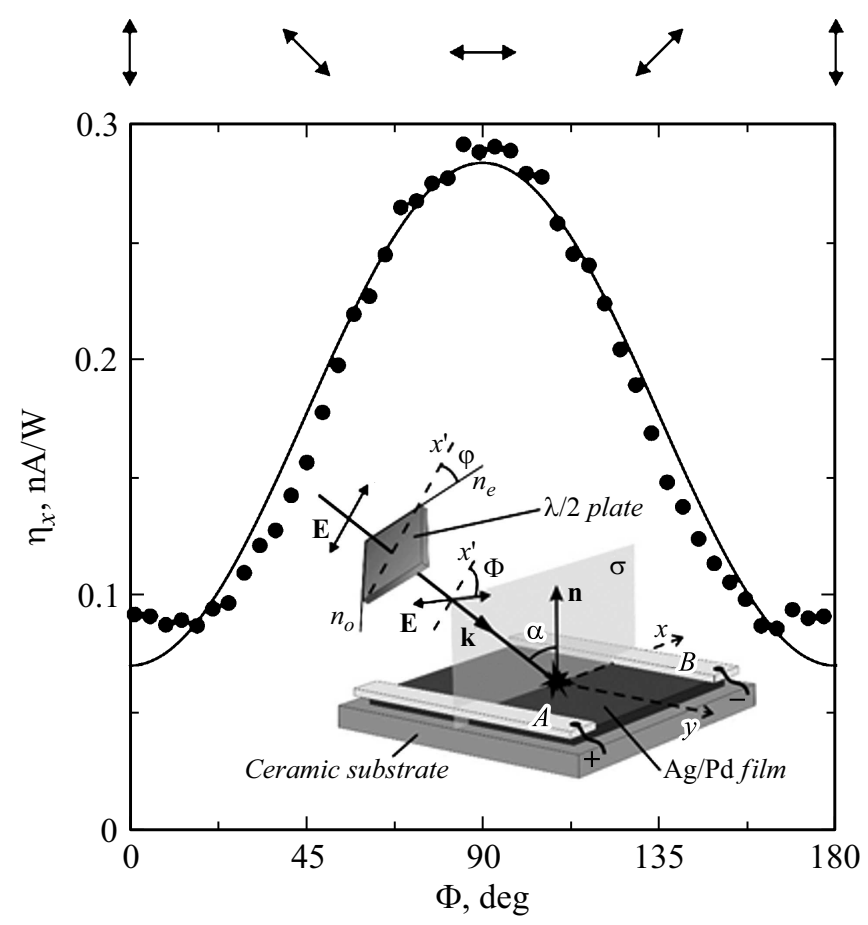

Рис. 1. Зависимость коэффициента $\eta_{x}$ преобразования лазерной мощности в продольный фототок на длине волны $1550 \mathrm{~nm}$. Точки - эксперимент, кривая - аппроксимирующая функция $\eta_{x}=0.107[1.66-\cos (2 \Phi)]$. Сверху показана ориентация плоскости поляризации при различных $\Phi)$. На вставке - геометрия эксперимента: $\mathbf{E}-$ вектор напряженности электрического поля, $\mathbf{k}-$ волновой вектор, $\varphi-$ угол поворота пластинки $\lambda / 2$ относительно плоскости падения $\sigma$, $\Phi-$ угол между $\sigma$ и $\mathbf{E}(\Phi=2 \varphi), \alpha-$ угол падения, $\mathbf{n}-$ нормаль к поверхности пленки, $A$ и $B-$ измерительные электроды, $x y-$ прямоугольная система координат (оси $x$ и $x^{\prime}$ лежат в плоскости $\sigma$ ).

фототок, возбужденный $p$-поляризованным импульсным излучением, имеет вид положительного однополярного импульса. При $\lambda=1670 \mathrm{~nm}$ и $p$-поляризации на переднем фронте положительного импульса фототока возникает отрицательный импульс. С увеличением $\lambda$ амплитуда и длительность этого отрицательного импульса претерпевают существенные

Письма в ЖТФ, 2018, том 44, вып. 18 


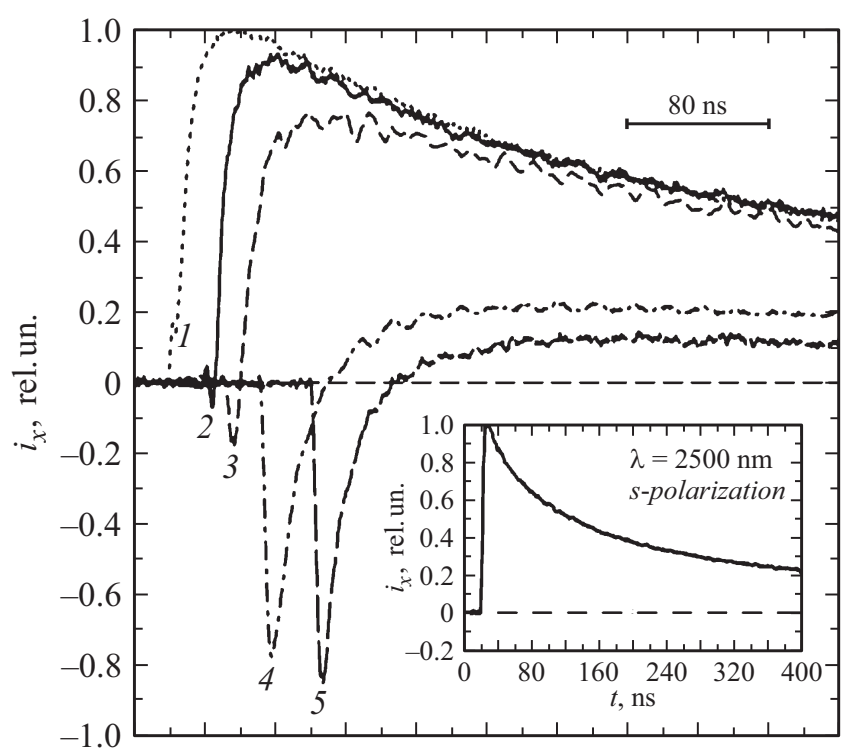

Рис. 2. Временнб́е формы импульсов фототока при р-поляризации на длинах волн 1500 (1), 1670 (2), 1900 (3), 2600 (4), $3600 \mathrm{~nm} \mathrm{(5),} \mathrm{сдвинутые}$ относительно друг друга по временно́й шкале на произвольную величину, а также временна́я форма импульса фототока при $s$-поляризации на длине волны $2500 \mathrm{~nm}$ (на вставке). Мгновенные значения импульсов фототока нормированы на разницу между их минимальным и максимальным значениями.

изменения. В итоге, как видно из рис. 2 (осциллограмма 3), при $\lambda=1900 \mathrm{~nm}$ импульс фототока представляет собой ярко выраженный двуполярный импульс. Его передняя часть состоит из короткого отрицательного импульса, а задняя часть представляет собой положительный импульс, длительность которого существенно больше длительности отрицательного импульса. С увеличением $\lambda$ амплитуда положительного импульса монотонно уменьшается.

На рис. 3 представлено отношение $\mu$ амплитуд отрицательной и положительной частей двуполярного импульса фототока в зависимости от $\lambda$. Видно, что зависимость $\mu(\lambda)$ носит немонотонный характер и имеет максимальное значение при $\lambda=3200 \mathrm{~nm}$. В диапазоне длин волн $3400-3800 \mathrm{~nm}$ отношение $\mu$ резко уменьшается и при 


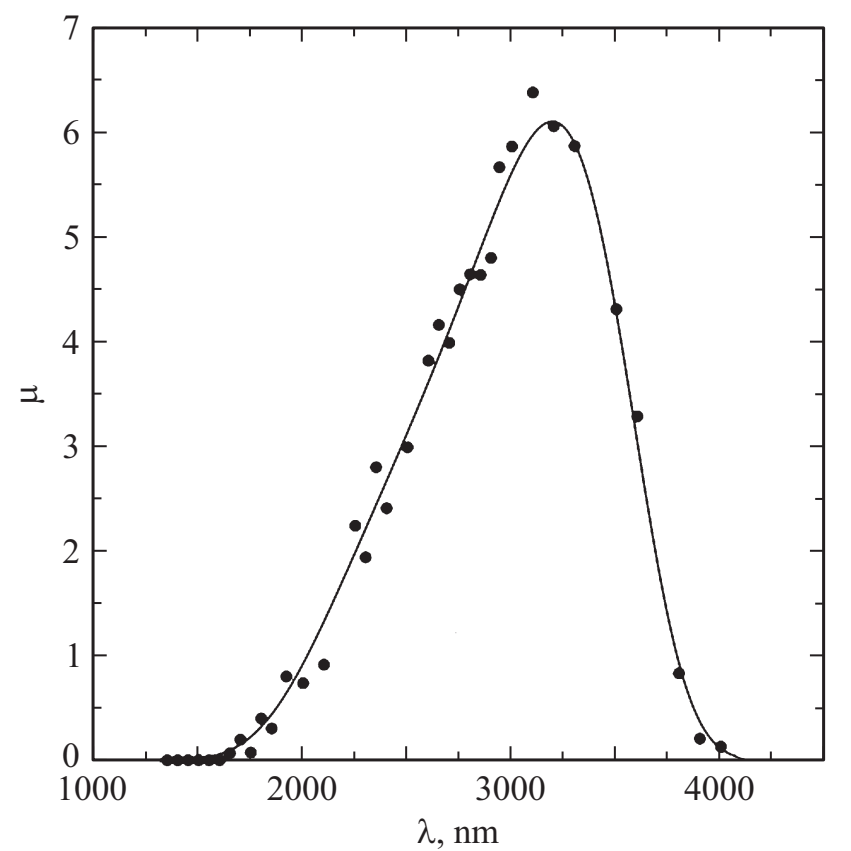

Рис. 3. Зависимость отношения $\mu$ амплитуд отрицательной и положительной частей импульса фототока при р-поляризации от длины волны $\lambda$.

$\lambda=4000 \mathrm{~nm}$ становится близким к нулю. Таким образом, двуполярный импульс при $p$-поляризованном излучении наблюдается в диапазоне длин волн $1670-4000 \mathrm{~nm}$.

Представленные выше результаты нельзя объяснить только с привлечением механизма генерации фототока за счет ЭУ. Действительно, фототок ЭУ пропорционален поглощенной лазерной мощности, т.е. чем больше поглощенная мощность, тем больше фототок [1]. Хорошо известно, что для проводящих материалов, например для металлов, для любого угла падения коэффициент отражения при $s$-поляризации больше, чем при $p$-поляризации. Следовательно, коэффициент поглощения при $s$-поляризации меньше, чем при $p$-поляризации, что должно приводить к уменьшению фототока ЭУ при переходе от $p$-поляризации к

Письма в ЖТФ, 2018, том 44, вып. 18 
$s$-поляризации. Однако, как видно из рис. 1 , фототок при $s$-поляризации больше, чем при $p$-поляризованной накачке.

Известно, что одновременно с фототоком за счет ЭУ может протекать фототок за счет поверхностного фотогальванического эффекта (ПФГЭ) $[2,6,18]$. ПФГЭ является результатом комбинации двух явлений: анизотропии распределения фотовозбужденных электронов по импульсам при их переходе из валентной зоны в зону проводимости и диффузного рассеяния этих электронов поверхностью [19]. Фототок $i_{x}$, обусловленный ПФГЭ, имеет следующую поляризационную зависимость [2]:

$$
i_{x} \propto(1+\cos 2 \Phi) .
$$

Из формулы (1) следует, что при $\Phi=90^{\circ}$, т.е. при $s$-поляризации, фототок, обусловленный ПФГЭ, исчезает.

Из теории ЭУ и ПФГЭ [2] следует, что при линейной поляризации направления продольных фототоков, возникающих при этих эффектах, должны быть противоположными. Для геометрии эксперимента и электрической схемы, представленной на рис. 1, фототок, обусловленный ЭУ, должен быть направлен вдоль оси $x$. В соответствии с рис. 2 импульс фототока при $\lambda<1670 \mathrm{~nm}$ действительно имеет положительную полярность. Теперь представим, что фототок возбуждается одновременно по обоим механизмам. В этом случае можно записать следующее соотношение: $i_{x}=i_{x, \mathrm{PDE}}-i_{x, \mathrm{SPGE}}$, где $i_{x, \mathrm{PDE}}, i_{x, \mathrm{SPGE}}-$ фототоки, обусловленные ЭУ и ПФГЭ соответственно. При $s$-поляризации $i_{x, s, \mathrm{SPGE}}=0$; следовательно, полный ток при $s$-поляризации $i_{x, s}=i_{x, s, \mathrm{PDE}}$. При $p$-поляризации фототок ПФГЭ $i_{x, p, \mathrm{SPGE}}$ не равен нулю; следовательно, полный ток при $p$-поляризации $i_{x, p}=i_{x, p \text {, PDE }}-i_{x, p, \mathrm{SPGE}}$, где $i_{x, p, \text { PDE }}-$ фототок ЭУ при $p$-поляризации возбуждающего излучения. Отсюда следует, что возможно выполнение неравенства $i_{x, s, \mathrm{PDE}}>i_{x, p, \text { PDE }}-i_{x, p, \mathrm{SPGE}}$, обеспечивающего выполнение условия $i_{x, s}>i_{x, p}$. Таким образом, поляризационную зависимость фототока, представленную на рис. 1 , можно объяснить возрастанием амплитуды импульса фототока ПФГЭ, имеющего противоположную полярность по отношению к импульсу ЭУ, при переходе от $s$-поляризованного к p-поляризованному излучению лазера.

Одновременное проявление ЭУ и ПФГЭ хорошо видно из осциллограмм, представляющих временнб́е формы импульсов фототока для $p$ - и $s$-поляризованного возбуждающего излучения при $\lambda>1670 \mathrm{~nm}$

Письма в ЖТФ, 2018, том 44, вып. 18 
(рис. 2). Из рис. 2 видно, что импульс фототока при $p$-поляризации для $\lambda>1670 \mathrm{~nm}$ является двуполярным, в то время как импульс фототока при $s$-поляризации независимо от $\lambda$ остается однополярным. Возникновение двуполярного импульса при $p$-поляризации можно объяснить одновременной генерацией однополярных импульсов фототока, имеющих противоположные полярности и разные амплитуды, а также различные время нарастания, длительность и время спада. Очевидно, что в зависимости от амплитудных и временны́х характеристик разнополярных импульсов импульс суммарного фототока также может быть однополярным, как это видно из осциллограммы, полученной при $p$ поляризации на длине волны $1500 \mathrm{~nm}$ (рис. 2, осциллограмма 1).

ПФГЭ в исследуемом нанокомпозите возникает за счет возбуждения электронов из валентной зоны в зону проводимости PdO. Ширина запрещенной зоны $E_{g}$ в $\mathrm{PdO}$ точно не установлена [20]. Однако в соответствии с данными работ $[21,22]$ она может находиться в диапазоне $0.6-0.8 \mathrm{eV}$. Известно, что $E_{g}$ наночастиц зависит от их размера (см., например, [23]). В нашем случае минимальный размер наночастиц $\mathrm{PdO}$ составляет $28 \mathrm{~nm}$. Очевидно, что в исследуемом образце имеются частицы значительно бо́льших размеров. Кроме того, частицы $\mathrm{PdO}$ находятся в окружении нанокристаллитов $\mathrm{Ag}-\mathrm{Pd}$, что также может привести к изменению $E_{g}$ нанокристаллитов $\mathrm{PdO}$ по сравнению с шириной запрещенной зоны сплошной пленки $\mathrm{PdO}$ [20]. Все это означает, что ПФГЭ в нанокомпозите $\mathrm{Ag} / \mathrm{Pd}$ может наблюдаться в широком диапазоне длин волн. Однако при относительно больших длинах волн, когда энергия кванта возбуждающего излучения меньше $E_{g}$ наночастиц PdO, наблюдение ПФГЭ становится невозможным, что демонстрирует зависимость $\mu(\lambda)$, представленная на рис. 3 .

Таким образом, импульс продольного фототока в нанокомпозитной пленке $\mathrm{Ag} / \mathrm{Pd}$ существенно зависит от поляризации и длины волны возбуждающего излучения. При $s$-поляризации накачки фототок, обусловленный ПФГЭ, исчезает и происходит генерация однополярного импульса фототока ЭУ в широком диапазоне длин волн. При $p$ поляризации одновременно возникают разнополярные импульсы фототока ЭУ и ПФГЭ, по-разному зависящие от длины волны лазерного излучения. В результате в зависимости от длины волны происходит генерация однополярного или двуполярного импульса фототока.

Письма в ЖТФ, 2018, том 44, вып. 18 
Работа выполнена при частичной финансовой поддержке госзадания ИМ УдмФИЦ УрО РАН (№ гос. рег. ААА-А16-116031110138-0), РФФИ (проект № 18-32-00224) и Финской академии наук (грант N 309672).

\section{Список литературы}

[1] Данишевский А.М., Кастальский А.А., Рывкин С.М., Ярошецкий И.Д. // ЖЭТФ. 1970. Т. 58. В. 2. С. 544-550.

[2] Gurevich V.L., Laiho R. // ФТT. 2000. T. 42. В. 10. С. 1762-1767.

[3] Берегулин Е.В., Валов П.М., Рывкин С.М., Ярошецкий И.Д., Лискер И.С., Пукшанский А.Л. // Письма в ЖЭТФ. 1977. Т. 25. В. 2. С. 113-116.

[4] Vengurlekar A.S., Ishihara T. // Appl. Phys. Lett. 2005. V. 87. N 9. P. 091118.

[5] Karch J., Olbrich P., Schmalzbauer M., Zoth C., Brinsteiner C., Fehrenbacher M., Wurstbauer U., Glazov M.M., Tarasenko S.A., Ivchenko E.L., Weiss D., Eroms J., Yakimova R., Lara-Avila S., Kubatkin S., Ganichev S.D. // Phys. Rev. Lett. 2010. V. 105. N 22. P. 227402.

[6] Obraztsov P.A., Mikheev G.M., Garnov S.V., Obraztsov A.N., Svirko Yu.P. // Appl. Phys. Lett. 2011. V. 98. N 9. P. 091903.

[7] Mikheev G.M., Nasibulin A.G., Zonov R.G., Kaskela A., Kauppinen E.I. // Nano Lett. 2012. V. 12. N 1. P. 77-83.

[8] Noginova N., Rono V., Bezares F.J., Caldwell J.D. // New J. Phys. 2013. V. 15. N 11. P. 113061.

[9] Durach M., Noginova N. // Phys. Rev. B. 2016. V. 93. N 16. P. 161406(R).

[10] Akbari M., Onoda M., Ishihara T. // Opt. Express. 2015. V. 23. N 2. P. 823-832.

[11] Михеев Г.М., Стяпшин В.М. // Приборы и техника эксперимента. 2012. № 1. C. 93-97.

[12] Akbari M., Ishihara T. // Opt. Express. 2017. V. 25. N 3. P. 2143-2152.

[13] Glazov M.M., Ganichev S.D. // Phys. Rep. 2014. V. 535. N 3. P. 101-138.

[14] Михеев Г.М., Саушин А.С., Зонов Р.Г., Стяпшин В.М. // Письма в ЖТФ. 2014. T. 40. B. 10. C. $37-45$.

[15] Михеев Г.М., Саушин А.С., Ванюков В.В. // Квантовая электроника. 2015. T. 45. № 5. C. 635-639.

[16] Михеев Г.М., Зонов Р.Г., Александров В.А. // Письма в ЖТФ. 2010. Т. 36. B. 14. C. $79-87$.

[17] Михеев Г.М., Саушин А.С., Гончаров О.Ю., Дорофеев Г.А., Гильмутдинов Ф.З., Зонов Р.Г. // ФТТ. 2014. Т. 56. В. 11. С. 2212-2218.

[18] Михеев Г.М., Стлпшин В.М., Образцов П.А., Хестанова Е.А., Гарнов С.В. // Квантовая электроника. 2010. Т. 40. № 5. С. 425-430.

[19] Альперович В.Л., Белиничер В.И., Новиков В.Н., Терехов А.С. // ЖЭТФ. 1981. T. 80. В. 6. С. $2298-2311$. 
[20] McBride J.R., Hass K.C., Weber W.H. // Phys. Rev. B. 1991. V. 44. N 10. P. 5016-5028.

[21] Nilsson P.O., Shivaraman M.S. // J. Phys. C. 1979. V. 12. N 6. P. 1423-1427.

[22] Ahuja R., Auluck S., Johansson B., Khan M.A. // Phys Rev. B. 1994. V. 50. N 4. P. 2128-2132.

[23] Sadovnikov S.I., Gusev A.I. // J. Alloys Compd. 2013. V. 573. P. 65-75.

Письма в ЖТФ, 2018, том 44, вып. 18 